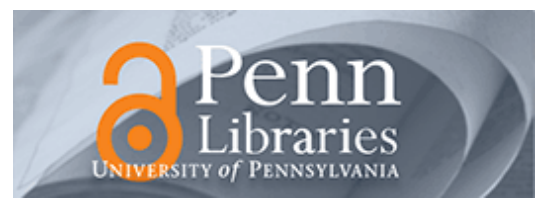

University of Pennsylvania

ScholarlyCommons

Operations, Information and Decisions Papers

Wharton Faculty Research

6-2009

\title{
Highbrow Films Gather Dust: Time-Inconsistent Preferences and Online DVD Rentals
}

Katherine L. Milkman

University of Pennsylvania

Todd Rogers

Max H. Bazerman

Follow this and additional works at: https://repository.upenn.edu/oid_papers

Part of the Other Business Commons, and the Recreation Business Commons

\section{Recommended Citation}

Milkman, K. L., Rogers, T., \& Bazerman, M. H. (2009). Highbrow Films Gather Dust: Time-Inconsistent Preferences and Online DVD Rentals. Management Science, 55 (6), 1047-1059. http://dx.doi.org/10.1287/ mnsc. 1080.0994

At the time of publication, author Katherine L. Milkman was affiliated with the Harvard Business School, Harvard University. Currently (July 2016), he is a faculty member in the Operation, Information and Decision Making Department of the Wharton School at the University of Pennsylvania.

This paper is posted at ScholarlyCommons. https://repository.upenn.edu/oid_papers/161

For more information, please contact repository@pobox.upenn.edu. 


\title{
Highbrow Films Gather Dust: Time-Inconsistent Preferences and Online DVD Rentals
}

\begin{abstract}
We report on a field study demonstrating systematic differences between the preferences people anticipate they will have over a series of options in the future and their subsequent revealed preferences over those options. Using a novel panel data set, we analyze the film rental and return patterns of a sample of online DVD rental customers over a period of four months. We predict and find that should DVDs (e.g., documentaries) are held significantly longer than want DVDs (e.g., action films) within customer. Similarly, we also predict and find that people are more likely to rent DVDs in one order and return them in the reverse order when should DVDs are rented before want DVDs. Specifically, a 1.3\% increase in the probability of a reversal in preferences (from a baseline rate of $12 \%$ ) ensues if the first of two sequentially rented movies has more should and fewer want characteristics than the second film. Finally, we find that as the same customers gain more experience with online DVD rentals, the extent to which they hold should films longer than want films decreases. Our results suggest that present bias has a meaningful impact on choice in the field, and that people may learn about their present bias with experience and, as a result, gain the capacity to curb its influence.
\end{abstract}

\section{Keywords}

want/should, intrapersonal conflict, time-inconsistent preferences, present bias, learning

\section{Disciplines}

Other Business | Recreation Business

\section{Comments}

At the time of publication, author Katherine L. Milkman was affiliated with the Harvard Business School, Harvard University. Currently (July 2016), he is a faculty member in the Operation, Information and Decision Making Department of the Wharton School at the University of Pennsylvania. 
H A R VAR D

\section{Highbrow Films Gather Dust: Time-inconsistent Preferences and Online DVD Rentals}

Katherine L. Milkman

Todd Rogers

Max H. Bazerman

\section{Working Paper}

07-099 


\title{
Highbrow Films Gather Dust: Time-inconsistent Preferences and Online DVD Rentals
}

\author{
Katherine L. Milkman \\ Harvard Business School, Harvard University, Boston, Massachusetts 02163, kmilkman@fas.harvard.edu \\ Todd Rogers \\ Analyst Institute, Arlington, VA 22209, trogers@analystinstitute.org \\ Max H. Bazerman \\ Harvard Business School, Harvard University, Boston, Massachusetts 02163, mbazerman@hbs.edu
}

\begin{abstract}
We report on a field study demonstrating systematic differences between the preferences people anticipate they will have over a series of options in the future and their subsequent revealed preferences over those options. Using a novel panel data set, we analyze the film rental and return patterns of a sample of online DVD rental customers over a period of four months. We predict and find that should DVDs (e.g., documentaries) are held significantly longer than want DVDs (e.g., action films) within-customer. Similarly, we also predict and find that people are more likely to rent DVDs in one order and return them in the reverse order when should DVDs are rented before want DVDs. Specifically, a 2\% increase in the probability of a reversal in preferences (from a baseline rate of $12 \%$ ) ensues if the first of two sequentially rented movies has more should and fewer want characteristics than the second film. Finally, we find that as the same customers gain more experience with online DVD rentals, the extent to which they hold should films longer than want films decreases. Our results suggest that myopia has a meaningful impact on choice in the field and that people may learn about their myopia with experience, and, as a result, gain the capacity to curb its influence.
\end{abstract}

Key words: want/should; intrapersonal conflict; time-inconsistent preferences; myopia; learning History: This paper was first submitted 11/11/07 and has been with the authors for 0.2 years for 2 revisions.

\section{Introduction}


Throughout our lives, we face many choices between things we know we should do and things we want to do: whether or not to visit the gym, whether or not to smoke, whether to order a greasy pizza or a healthy salad for lunch, and whether to watch an action-packed blockbuster or a history documentary on Saturday night. In this paper, we investigate the effects of this type of internal conflict between the desire to do what will provide more short-term utility and the knowledge that it is in our long-term interest to do something else. In particular, we focus on the way this type of conflict leads individuals to make systematically different decisions in the domain of film rentals when they make choices in the present about what to watch versus choices for the future about what to rent.

A number of authors have discussed the distinction between goods that provide primarily long-term benefits, which we call should goods, and goods that provide primarily short-term value, which we call want goods. Options conceptually similar to shoulds have also been called "cognitive," "utilitarian," "virtue," "affect-poor," and "necessity" options, while options that are conceptually similar to wants have also been called "affective," "hedonic," "vice," "affect-rich," and "luxury" options (see Khan, Dhar and Wertenbroch, 2005 for a review). We rely on the terms should and want to convey the internal tension produced by these competing options. The distinction between these different types of goods is important because evidence suggests that the context in which a decision is made may affect which types of goods, should goods or want goods, a person prefers.

The tendency to put off options preferred by our should selves (e.g., saving, eating vegetables) in favor of options preferred by our want selves (e.g., spending, eating ice cream) is stronger for decisions that will take effect immediately than decisions that will take effect in the future (Loewenstein, 1996; Bazerman, Tenbrunsel, and Wade-Benzoni, 1998). Economists have modeled this phenomenon by proposing that people dramatically discount future utility relative to present utility (see for example Phelps and Pollak, 1968; Ainslie, 1992; Loewenstein and Prelec, 1992; Laibson, 1996; O’Donoghue and Rabin, 1999) and with "multiple-selves" models in which individuals' decisions are controlled by multiple internal agents with competing preferences, one of which optimizes over a longer time horizon than the other 
and is more likely to control choices that are made for the future than the present (see for example Thaler and Shefrin, 1981; Read, 2001; Fudenberg and Levine, 2006). In this paper, we empirically test for the time-inconsistent preferences that these models of myopia predict people will demonstrate when making repeated choices over the same set of goods, ranging from extreme want goods (items with only shortterm benefits) to extreme should goods (items with only long-term benefits) when some decisions will take effect in the present and some will take effect in the future.

Evidence that people prefer want options over should options more frequently when making choices about the short-run rather than the long-run has been found in numerous domains (Oster and Scott Morton, 2005; Wertenbroch, 1998; Rogers and Bazerman, 2008; Read and Van Leeuwen, 1998; Milkman, Rogers, and Bazerman, 2007), including that of film rentals in a laboratory setting (Read, Loewenstein and Kalyanaraman, 1999; Khan, 2007). To extend the study of the impact of myopia on people's preference rankings of want and should options beyond the laboratory, we obtained a novel panel data set containing individual-level information about consumption decisions over a period of four months from Quickflix, an Australian online DVD rental company. This data set comes from a domain in which individuals make rental choices for the future and consumption choices for the present from a set of goods that range from extreme should items (highbrow films) to extreme want items (lowbrow films). Repeated observations of the same individuals over time allow us to investigate both whether customers exhibit myopia and whether they learn to reduce their myopia with experience.

To test the theory that people exhibit myopia in the domain of film rentals, we begin by scoring the films in our data set on the spectrum from should to want items. We then use our rental data to test and confirm the hypothesis that the same Quickflix customer holds films longer the closer the films fall to the should end of the want/should spectrum. We also test and confirm the hypothesis that when customers rent two sequential films, the first of which has more should and fewer want characteristics than the second film, they are more likely to reverse their preferences (watching and returning the films out of order) than when they rent a movie with more want and fewer should characteristics first. Both of these 
hypotheses stem from the combination of a model of consumers as myopic and our definition of relative should and want goods. We thus interpret our findings as evidence that people exhibit myopia in the field when making decisions about film rentals. Finally, we address and attempt to rule out a number of alternative explanations for our findings. In the process, we determine that consumers reduce the extent to which they hold films that fall closer to the should end of the want/should spectrum longer than other DVDs as they gain rental experience, suggesting that people learn about their myopia over time and that the effects we detect are unlikely the result of "optimal" decision making strategies.

The rest of this paper is organized as follows. Section 2 reviews the relevant literature on timeinconsistent preferences and clarifies the origins of our hypotheses. In Section 3, we describe our data set and methods for rating films along the spectrum from should to want. We present the results of our analyses and discuss alternative explanations for our findings in Section 4 and present our conclusions in Section 5.

\section{Past Research on Time-inconsistent Preferences}

A considerable literature on time-inconsistent preferences has developed since Strotz (1956) pointed out that people exhibit more impatience when making decisions that will take effect in the shortrun rather than the long-run. Loewenstein and Thaler (1989), Ainslie (1992), O’Donoghue and Rabin (1999), and Frederick et al. (2001) provide partial reviews of the literature on intertemporal choice, and Milkman, Rogers and Bazerman (2008) review the literature on the context effects that have been shown to alter people's preferences for should versus want options.

Evidence from numerous laboratory studies indicates that consumers behave myopically when making choices about money (McClure, Laibson, Loewenstein and Cohen, 2004; Thaler, 1981; Kirby and Herrnstein, 1995; Kirby and Marakovic, 1996; Kirby, 1997), lottery tickets (Read et al., 1999), relief from pain and irritation (Solnick, Kannenberg, Eckerman, and Waller 1980; Navarick, 1982; Trope and Fishbach, 2000), films (Read et al., 1999; Khan, 2007), and foods (Wertenbroch, 1998; Khan, 2007; Read and Van Leeuwen, 1998), among other things. Models of myopia have also been tested and confirmed in the 
field in the domains of gym attendance (Malmendier and Della Vigna, 2006), magazine newsstand and subscription pricing (Oster and Scott Morton, 2005; Wertenbroch, 1998), savings behavior (Angeletos, Laibson, Repetto, Tobacman, and Weinberg 2001; Ashraf, Karlan and Yin, 2006), and supermarket quantity discounts (Wertenbroch, 1998). Past field studies, however, have not directly tested whether people's preference rankings over a set of goods are systematically different in advance of consumption than at the time of consumption, as predicted by a combination of a model in which consumers dramatically discount utility from future periods and our definition of want and should options.

For a number of reasons, it is empirically difficult to test models of consumers as myopic outside the laboratory. A direct test of any such model requires a data set containing information about the consumption decisions of the same consumers over time, where different decisions take effect at different points in the future. Past field studies have overcome the hurdle of obtaining individual-level consumption data over time in the domains of savings behavior and gym attendance. Partnering with a bank in the Philippines, Ashraf et al. (2006) offered commitment savings products to a subset of the bank's former clients. They confirm (for female subjects) the prediction that consumers who exhibit more myopia on hypothetical questions are more likely to take up commitment devices. Ashraf et al. (2006) track individuals' take up of a savings commitment device as well as the amount individuals save in their bank accounts over a 12-month period. Malmandier and Della Vigna (2006) employ a panel data set to examine individual-level gym attendance and contract types over a three-year period at several health clubs. They find that myopia explains the popularity of flat-fee contracts among gym customers who could have saved money by paying per-visit. While neither of these studies employs data that would permit the identification of explicit reversals in preferences at the within-subject level, both test predictions of models of myopia in the field at the within-subject level. Both studies also examine the choice of whether or not to engage in a should behavior, but not the way in which people dynamically change their preferences over a set of options ranging from those with more want characteristics to those with more should characteristics, which is the phenomenon examined in this paper. 
Tests of the hypothesis that individuals are myopic using between-subject data are less challenging to perform in the field than tests employing within-subject data. Angeletos et al. (2001) use data from the Panel Study of Income Dynamics to evaluate the relative performance of the competing hyperbolic and exponential time-discount function models. As compared to the exponential discount function, which does not allow for myopia, they find that that the hyperbolic discount function, which models consumers as myopic, offers a better approximation of the data on household liquid wealth, credit card borrowing, and changes in consumption in response to predictable changes in income. In another between-subject field study of myopia, Oster and Scott Morton (2005) examine the newsstand and subscription pricing of should and want magazines (which they call "meritorious magazines" and "magazines for which consumers might have a time-inconsistency problem," respectively). The authors find, as models of myopia predict, that should magazines have a higher subscription-to-newsstand price ratio than want magazines. Finally, Wertenbroch (1998) examines the quantity discounts applied to a matched sample of 30 virtue (should) and 30 vice (want) supermarket goods and finds that, consistent with models of myopia in which consumers are assumed to be sophisticated about their self-control problems, want goods are, on average, subject to steeper quantity discounts than should goods. He also estimates the price elasticity of demand for a sample of paired vice (want) and virtue (should) groceries using a year of supermarket scanner data. Again, consistent with models of myopia, Wertenbroch finds that demand for should goods is more price sensitive than demand for want goods. However, all of these studies are tests of the implications of models of myopia on outcomes that are one or more levels removed from individuals' actual choices.

In our study, we attempt to combine the approaches of Wertenbroch (1998) and Oster and Scott Morton (2005), who examine the implications of models of myopia in field domains where consumers are faced with ranking their preferences over a range of goods, with the approaches of Ashraf (2006) and Malmandier and Della Vigna (2006), who use within-subject data sets to test various predictions of models of myopia in the field. The central hypotheses of this paper and the domain of interest were inspired by Read et al. (1999), who conduct a laboratory experiment to show that when choosing a film for imme- 
diate consumption, people more often prefer movies with more want characteristics and fewer should characteristics than when selecting a film for delayed consumption. Others have hypothesized that online DVD rental customers might exhibit a tendency to hold highbrow films longer than lowbrow films (see Phillips, 2006; Tugend, 2006; and Goldstein and Goldstein, 2006), but none have presented empirical support for their conjectures. Our goal is to provide the first direct, within-subject field test of whether consumers exhibit myopia in a domain where their choice set includes options ranging from want to should items. In addition, we look for evidence that customers learn about their myopia as they gain experience.

Models of myopia suggest that given a set of options, an option that provides more long-term benefits (a should option) will be relatively more attractive than an option that provides more short-term benefits (a want option) when a choice is made for the future than when that same choice is made for the present. Since the decision of which film from a collection to watch first (and thus return first) is a choice made over a set of options for the present, theories of myopia lead to the following hypothesis:

H1: The closer a film falls to the should end of the want/should spectrum, the longer a customer will postpone watching and thus returning it.

Similarly, since the decision of which film to rent is a choice made for the future, but the decision of which film to watch (and thus return first) is made for the present, theories of myopia lead to the following hypothesis:

H2: The probability that a customer will return two sequentially rented films out of order increases as the first film rented becomes more of a should on the want/should spectrum relative to the second film.

Finally, in an attempt to rule out the possibility that individuals have a rational reason for holding more extreme should films longer than other films, we look for evidence that customers learn to reduce the extent to which they exhibit this tendency as they gain experience with online DVD rentals. If it were optimal for customers to hold more extreme should films longer than others, we would not expect expe- 
rience to diminish this effect. Past research on commitment devices has shown that some myopes are sophisticated about their self-control problems and willing to incur costs to reduce the effects of their myopia (Wertenbroch, 1998; Ariely and Wertenbroch, 2002; Ashraf et al., 2006). These results raise the question of whether people gain sophistication about their myopia through experience. It has been demonstrated in a number of domains that people have the ability to learn from experience to reduce their decision making errors (Lichtenstein \& Fischhoff, 1980; Erev and Roth, 1998). As we address potential alternative "rational" explanations for our results, we look for evidence that as customers gain experience renting DVDs, they reduce the extent to which they procrastinate about watching films that fall closer to the should end of the want/should spectrum more than others.

\section{Methods}

\subsection{Data Set}

We obtained a novel panel data set from Quickflix, the second largest online DVD rental company in Australia, containing information about the individual choices made by the company's customers between March 1, 2006 and June 30, 2006. Customers in the most popular Quickflix subscription plan pay a flat fee each month to hold three exchangeable films in their homes, and they may hold the movies they rent for an unlimited length of time without incurring late fees. To ensure that all customers in our data set are subject to the same incentives with regard to their film rental and return behavior, we conduct our analyses only on customers in Quickflix's most popular plan. Quickflix offers a selection of over 15,000 movie titles, and each customer maintains a "queue," or an ordered list of the movies she would like to rent. When a customer returns one film, Quickflix immediately sends that customer the film listed at the top of her queue. When a customer's first choice is unavailable, the next highest film in her queue is sent instead. For a typical subscriber, the net turn-around time for a film exchange is two days, and postage is paid by Quickflix.

Our data set includes the day-to-day records of people's film rentals and returns over a fourmonth period. Although our rental data set ends on June 30, 2006, we have records of the dates when 
each of the films rented during the relevant time period was returned. Quickflix also provided us with unique identifiers for each customer and with descriptive information about each film in its database. During the four-month period included in our data set, a total of 4,474 different customers participated in Quickflix's most popular three-at-a-time unlimited DVD rental plan, renting a total of 101,545 DVDs (an average of 22.7 per customer). On average, these customers held the DVDs they rented for 12 days, and $90 \%$ of movies were held between 4 and 32 days.

\subsection{Assigning Films Continuous Should/Want Scores}

To test our hypotheses about how films' positions on the should/want spectrum affect both (a) the order in which they are returned relative to the order in which they were rented and (b) how long it takes customers to return them, we must create a measure of the extent to which a film is a should versus a want. We first create separate scores for films on a should spectrum and a want spectrum and then subtract films' want scores from their should scores to measure where each film fits on the spectrum from an extreme should option to an extreme want option. ${ }^{1}$

To generate a measure of each Quickflix film's should minus want score, we borrow data from a previous research project. For that project, 145 anonymous American volunteers who signed up to participate in online paid polls administered by Harvard Business School's Computer Lab for Experimental Research (CLER) were paid $\$ 15$ to give should and want scores to a random sample of 60 films from a database of 1,040 movies. Raters ranged in age from 18 to 45 , with an average age of 25 , and $70 \%$ of raters were female. After being provided with concept definitions, subjects in this study were first asked to give 60 films want/(should) ratings ranging from 1 to 7 and were then asked to give the same set of 60 films should/(want) ratings ranging from 1 to 7 (see Appendix for more details). The order in which subjects were asked to rate the 60 films was randomized, as was the sequence in which they provided should

\footnotetext{
${ }^{1}$ Through pre-testing we determined that the extent to which a film is a should film (based on how much long-term value it provides) is most easily evaluated distinctly from the extent to which it is a want film (based on how much short-term value it provides). However, the variable of interest in this study is where on the spectrum from an extreme should to an extreme want a film lies, which theories of myopia suggest will predict the extent to which it is preferred when choices are made for the future versus the present.
} 
and want ratings (50\% gave films should ratings first). Subjects saw the same information about a film that they would have seen if they had searched for it on the website of the American online DVD rental company Netflix. We provided subjects with an incentive to provide accurate ratings of films by paying them for performance. For each film a survey participant classified within one point of the average rating across respondents, her "accuracy score" was increased by one. The $20 \%$ of participants who received the highest accuracy scores received a $\$ 10$ bonus payment.

Five hundred of the 1,040 movies from this survey were also films in the Quickflix DVD rental database. Since the films subjects rated were randomly selected, these 500 films were rated by varying numbers of subjects. An average of 8.58 survey participants rated each film (standard deviation $=3.02$ ).

To confirm that subjects provided us with reliable ratings of the movies in our survey database, we conduct an analysis of inter-rater reliability. Since we are interested in quantifying each film's should minus want score, we first calculate this difference variable for each film-rater pair. If our survey ratings contain a meaningful signal, the should minus want scores assigned by different survey participants to the same film should be more tightly clustered than the should minus want scores assigned by different survey participants to different films. We run a one-way analysis of variance (ANOVA) to compare ratings variation between films to ratings variation within film (Shrout and Fleiss, 1979). An intraclass correlation of 0.21 and an estimated reliability of a film should minus want score mean of 0.70 confirms that our survey averages are reliable: should minus want scores vary significantly more between films than within films. To check that participants understood from our definitions of want and should movies that, for the most part, extreme should movies are not extreme want movies and vice versa, we examine the correlation between a movie's average want score and its average should score. This correlation is highly significant and negative $(\rho=-0.22 ; p$-value $<0.001)$ across the 500 films in our sample, suggesting that our raters grasped the relationship between a typical movie's want and should characteristics.

To validate these scores and ensure that the incentives we provided to subjects for performance did not bias their ratings, we hired five research assistants to assign each of the 500 films in our sample 
want and should scores. These research assistants were provided with the same concept definitions as our original subjects and the same information about each film, and the order in which they rated films was randomized. Our research assistants were each paid a flat fee of $\$ 120$ for their time with no bonus pay for "accuracy." The Cronbach's alpha across these five raters' should minus want scores for the 500 films in our sample was 0.64 , indicating a high level of agreement. The correlation between the average should minus want scores produced by our original 145 subjects and our five research assistants across the 500 films in our database was 0.68 ( $\mathrm{p}$-value $<0.001$ ). This high correlation between the two sets of ratings gives us confidence that paying subjects for performance did not harm the reliability of the survey data we collected on films' should minus want scores.

In order to develop a should minus want score for each film in the Quickflix DVD library using the survey data from 145 subjects described above, we ran an ordinary least squares (OLS) regression to predict survey respondents' average should minus want scores of the 500 Quickflix films from our survey (see Table 1). We employed analytic weights in our regression to control for the fact that different numbers of subjects rated each film. The predictors in our regression include all of the quantifiable characteristics of a film that were provided to us by Quickflix: 21 genre dummy variables, the average subscriber's rating of the film, the number of years since the film was released in theatres, the number of days since the film was released on DVD, dummy variables indicating the film's OFLC rating, ${ }^{2}$ the number of characters in the film's title, and the number of other films in the Quickflix rental database that were released by the same studio. Regression (1) in Table 1 explains $44 \%$ of the variance in films' average should minus want scores.

We extrapolate from our sample of 500 films to the 17,258 films in the Quickflix movie database and give each film a should minus want score (SMW score) based on the coefficients in regression (1). According to this classification scheme, the movie with the lowest SMW score in our database is "The Story of Ricky," a violent, futuristic, sci-fi horror film from 1988, and a film that seems intuitively likely 
to be a strong want for anyone who would choose to rent it. The movie with the highest SMW score in our database is "Kokoda Frontline," an Australian, Oscar-winning documentary from 1942 about the Ko-

koda campaign in Papua New Guinea during World War II, a film that seems intuitively likely to be a strong should for anyone who would choose to rent it. We then standardize these scores across the 17,258

films in the Quickflix library.

Table 1

PREDICTING A MOVIE'S AVERAGE SHOULD MINUS WANT SCORE

\begin{tabular}{|c|c|}
\hline & $\begin{array}{l}\text { Average Should Minus } \\
\text { Want Score from Survey } \\
\text { (1) }\end{array}$ \\
\hline Intercept & -0.6128 \\
\hline Number of Characters in Film Title $\times 10^{2}$ & -0.5069 \\
\hline Number of Films Released by Same Studio in Quickflix Library $\times 10^{3}$ & 0.6732 \\
\hline Average User Rating of Film $\times 10^{2}$ & 0.5435 \\
\hline Years Since Film's Release in Theaters & $0.0216^{\star \star \star}$ \\
\hline Days Since Film's Release on DVD $\times 10^{4}$ & 0.5400 \\
\hline Film Rated R & $-1.4142^{\star \star \star}$ \\
\hline Film Rated PG & $-1.1275^{\star \star}$ \\
\hline Film Rated MA & $-0.9434^{\star \star}$ \\
\hline Film Rated M15 & -0.9854 \\
\hline Film Rated M & $-1.1670^{\star \star \star}$ \\
\hline Film Rated G & $-0.9747^{\star \star}$ \\
\hline Action Film & $-0.3636^{\star *}$ \\
\hline Adventure Film & -0.0448 \\
\hline Anime Film & 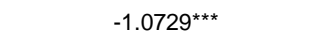 \\
\hline Arthouse Film & 0.0331 \\
\hline Australian Film & 1.1523 \\
\hline Children's Film & $-0.7641^{\star \star}$ \\
\hline Comedy Film & $-0.8284^{* \star *}$ \\
\hline Crime Film & $-0.7289 * \star \star$ \\
\hline Documentary Film & $1.9466^{\star \star \star}$ \\
\hline Drama Film & $0.4830^{\star \star *}$ \\
\hline Family Film & $-0.5135^{\star \star}$ \\
\hline Fantasy Film & -0.2983 \\
\hline Foreign Film & 0.3406 \\
\hline Horror Film & $-1.0109 * \star \star$ \\
\hline Lifestyle Film & 0.1081 \\
\hline Music Film & -0.0772 \\
\hline Performance Film & -0.8155 \\
\hline Romance Film & $-0.5658^{\star \star \star}$ \\
\hline Science Fiction Film & $-0.6727^{\star \star \star}$ \\
\hline Sports Film & -0.5500 \\
\hline Television Film & $-0.4422^{\star \star}$ \\
\hline Thriller Film & $-0.5886^{\star \star \star}$ \\
\hline Analytic Weights & Yes \\
\hline Observations & 500 \\
\hline $\mathbf{R}^{2}$ & 0.4392 \\
\hline
\end{tabular}

\footnotetext{
${ }^{2}$ The Australian Office of Film and Literature Classification (OFLC) provides films with ratings based on the offen-
} 


\section{Results}

\subsection{Holding Time}

We address the question of whether or not Quickflix customers exhibit the behavior predicted by models of myopia by running a series of regressions. First, we examine the influence of a movie's should minus want score on how many days a customer holds that film. A combination of a model of myopia with our definitions of relative want and should goods suggests that the higher a movie's should minus want score, the more likely a customer will be to postpone watching it, leading her to hold it longer. In Table 2, we present the results of an OLS regression estimating the relationship between the logarithm of how many days a customer holds a movie before returning it and that movie's should minus want score. ${ }^{3}$ In this regression, the explanatory variables include a measure of the movie's should minus want score, the rank of the movie in a customer's queue when it was shipped, the number of days the movie spent in the customer's queue before it was rented, the number of movies the customer had rented from Quickflix since January 1, 2006 when the movie was shipped, the length of the movie in question, dummies indicating the day of the week when the movie was shipped, and dummies indicating the week of the year when the movie was shipped. This regression also includes customer fixed effects, and standard errors are clustered by customer.

The coefficient on the SMW score of a film in regression (2) indicates that holding all else constant, a one standard deviation increase in a movie's SMW score is associated, on average, with a 2\% within-customer increase in how many days the movie is held. To put this in context, the results from regression (2) indicate that for the same customer, "Kokoda Frontline" will be held, on average, 17\% longer (an average of 1.5 days longer) than "Alien vs. Predator," a lowbrow 2005 action, sci-fi thriller that received one of the lowest should minus want scores of the 17,258 films in the Quickflix library. Figure 1 illustrates this result graphically. 
Table 2

THE EFFECT OF A MOVIE'S SMW SCORE ON HOLDING TIME

\begin{tabular}{lc}
\hline THE EFFECT OF A MOVIE'S SMW SCORE ON HOLDING TIME \\
\hline
\end{tabular}

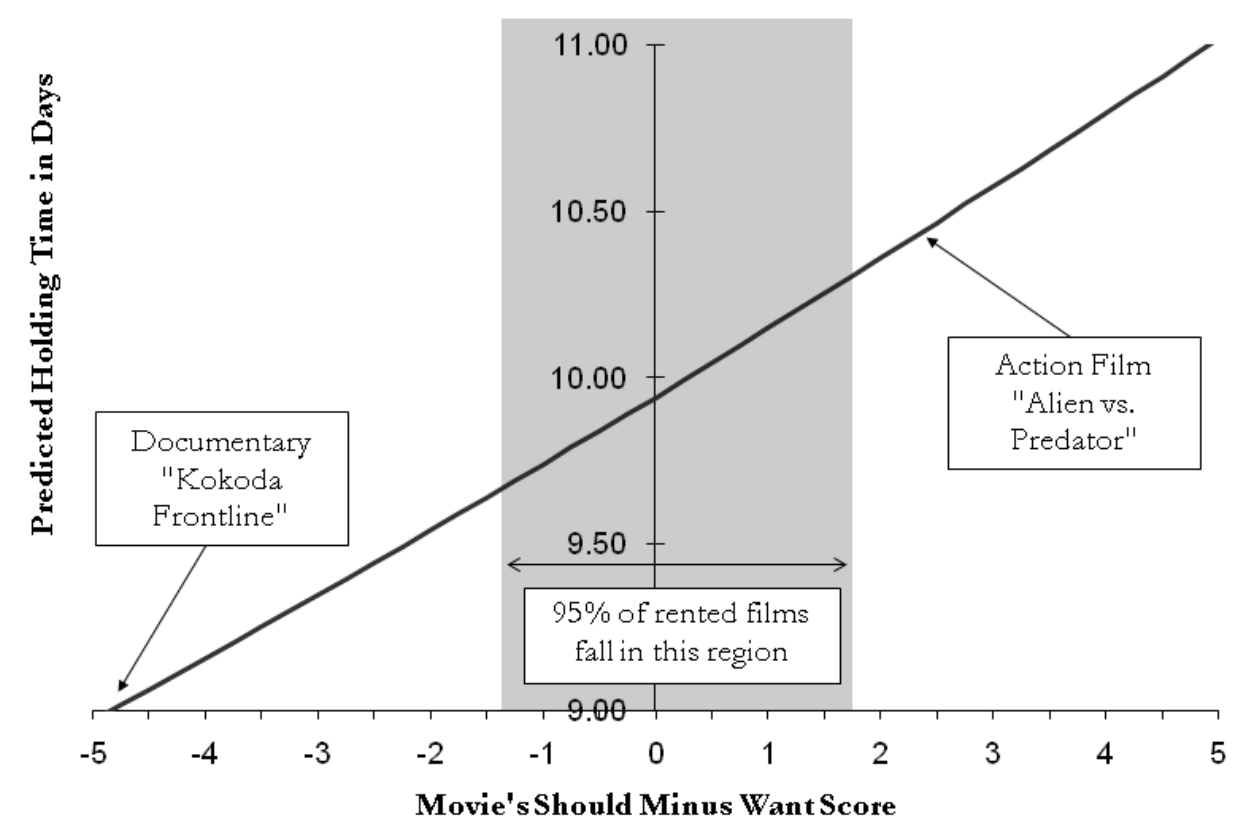

Figure 1: Illustration of the relationship between a film's SMW score and its predicted holding time.

\subsection{Reversals in Preferences}

\footnotetext{
${ }^{3}$ Our outcome variable is the logarithm of a movie's holding time rather than the raw holding time because it seems more appropriate to assume consumers increase the relative rather than the absolute holding time of a film based on its position along the should/want spectrum. However, our findings are robust to examining raw holding time.
} 
Next, we test the prediction that people are more likely to rent one movie before another but reverse the order in which those movies are watched (and thus returned) when the first movie rented receives a higher should minus want score than the second. In order to test this prediction we create a data set in which each observation corresponds to an instance in which a Quickflix customer rented two movies, one after the other, and the second movie was delivered to that customer at least one day before the first had been received by a Quickflix return center. We only include such an event in our data set if the first movie had a higher ranking in the customer's queue when it was mailed than the second movie, an indication that the customer explicitly preferred the first movie to the second when making a decision that would take effect in a future period about which movie to watch. Of the 14,132 sequential rentals in our resulting data set, we observe 1,753 reversals in preferences. To create a measure of how much more of a should movie and less of a want movie the first film rented is relative to the second film, we subtract the SMW score of the movie that was rented second (movie 2) from the SMW score of the movie that was rented first (movie 1). We call this variable the movie 1 SMW premium. Its mean value in our sample of sequentially rented movies is -0.002 and its standard deviation is 1.20 . Of the 7,086 sequential rentals in which the movie 1 SMW premium is positive, we observe reversals in preferences at a rate of 13.5\%; and of the 7,025 sequential rentals in which the movie 1 SMW premium is negative, we observe reversals in preferences at a rate of $11.2 \%$.

In Table 3, we present the results of two of ordinary least squares (OLS) regressions estimating the relationship between the probability of an intertemporal reversal in preferences and the movie 1 SMW premium over movie 2, controlling for the difference between the films' lengths and customer fixed effects and clustering standard errors by customer. Regression (3) demonstrates that for each additional standard deviation by which movie 1's SMW score exceeds that of movie 2, the probability of a reversal in preferences increase by $1 \%$ (an approximately $7 \%$ increase from the mean $12 \%$ probability of a reversal in preferences). See Figure 2 for an illustration of this effect. In regression (4), we replace our continuous measure of movie 1's should minus want premium over movie 2 with a dummy variable indicating 
whether or not movie 1's SMW score exceeds that of movie 2. Regression (4) demonstrates that when movie 1's SMW score exceeds movie 2's, the probability of a reversal in preferences is $2 \%$ higher than it would be otherwise (an approximately 15\% increase from the mean 12\% probability of a reversal in preferences). Running these analyses with a conditional logit model including customer fixed effects and clustered standard errors yields nearly identical results.

The increases in the likelihood of a reversal in preferences reported in Table 3 are conservative estimates of the effect we seek to quantify because many of the data points included in our analyses may not coincide with situations in which a customer had an actual opportunity to reverse her preferences. In some cases, movie 2 must have arrived in a customer's home after movie 1 had been watched or even mailed back to Quickflix. ${ }^{4}$ Each point included in our data set that corresponds to a situation in which a customer did not have an opportunity to reverse her preferences necessarily reduces the change in the probability of a reversal in preferences we are able to associate with a change in the movie 1 SMW premium.

\footnotetext{
${ }^{4}$ Because we know only the dates when return centers received films from customers and the dates when they shipped new movies to customers and not how long shipments spent in the mail, the best we can do is to assume all shipments spent one day in the mail, which is almost certainly an underestimate. Our finding that the probability of a preference reversal increases as the movie 1 SMW premium increases is sensitive to this assumption: the coefficient on our main effect increases, for example, the more days we assume shipments spend in the mail. However, such assumptions about shipment time, when false, might bias our results upward by selecting on films that have a tendency to spend longer in customers' homes, so we make the most conservative possible assumption about shipping time in the analyses we present.
} 
Table 3

THE EFFECT OF A MOVIE'S SMW SCORE ON REVERSALS IN PREFERENCES

\begin{tabular}{lcc}
\hline \hline & $\begin{array}{c}\text { Preference } \\
\text { Reversal } \\
\mathbf{( 3 )}\end{array}$ & $\begin{array}{c}\text { Preference } \\
\text { Reversal } \\
\mathbf{( 4 )}\end{array}$ \\
\hline Movie 1 Should Minus Want Premium & $0.009^{\star \star \star}$ & \\
Movie 1 Received a Higher SMW Score than Movie 2 & $(0.003)$ & $0.018^{\star \star \star}$ \\
Movie 1 Length in Minutes Minus Movie 2 Length in Minutes $\times \mathbf{1 0}^{\mathbf{3}}$ & & 0.006 \\
& 0.007 & 0.006 \\
Customer Fixed Effects & 0.026 & 0.026 \\
Observations & Yes & Yes \\
Customers & 14,132 & 14,132 \\
$\mathbf{R}^{\mathbf{2}}$ & 3,095 & 3,095 \\
\hline \hline
\end{tabular}

Columns (3) and (4) report OLS coefficients from a regression to predict whether or not a customer exhibited a reversal in preferences based on different measures of the should minus want scores of movies in the customer's choice set. Robust standard errors clustered at the customer-level are in parentheses. * ${ }^{\star *}$, and ${ }^{* \star *}$ denote significance at the 10 percent, 5 percent, and 1 percent levels, respectively.

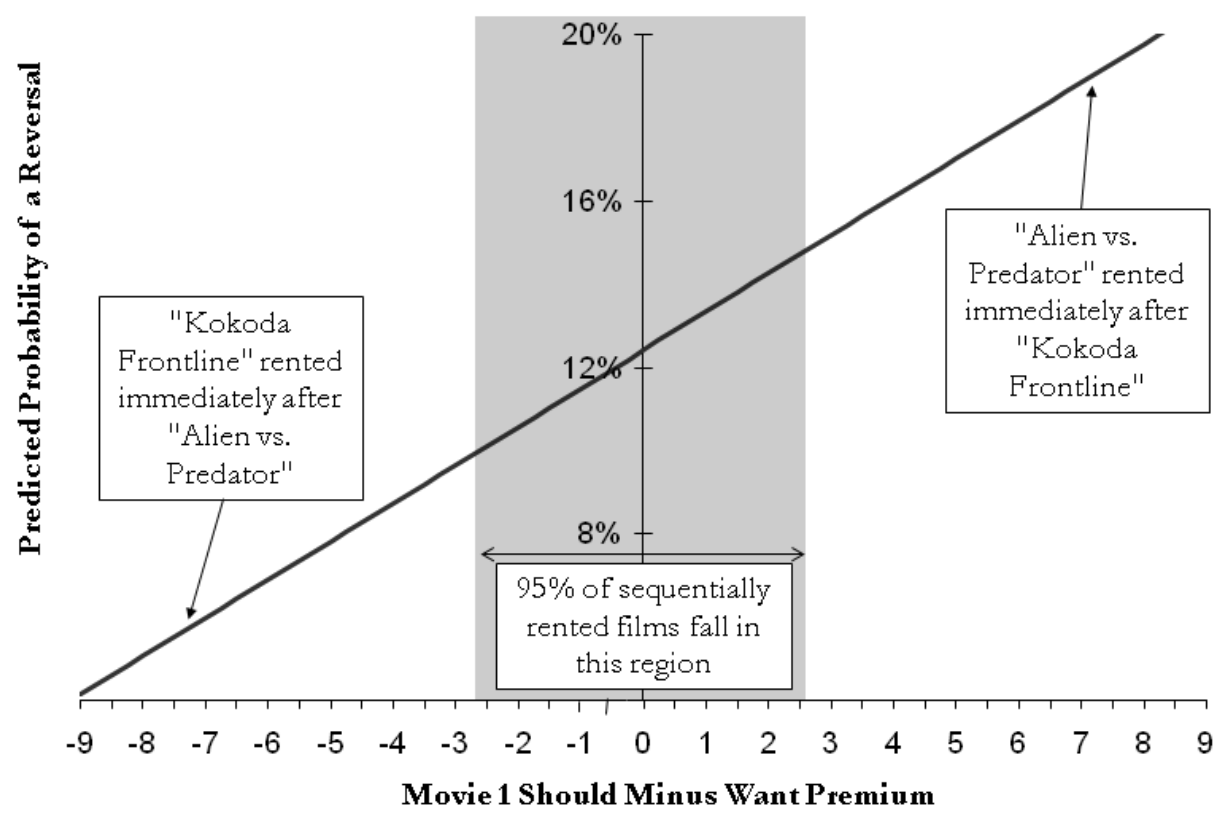

Figure 2: Illustration of the relationship between the movie 1 SMW premium when movie 1 is rented immediately before movie 2 and the predicted probability that a customer will reverse her preferences and return movie 2 before movie 1.

\subsection{Comparing Our Should Minus Want Score to Other Available Predictors of Holding Time}

We next investigate the extent to which our should minus want score captures the key components of a film that predict how long a Quickflix customer will postpone watching it. Regression (5) in Table 4 presents the result of an OLS regression conducted to predict the logarithm of the number of days a customer will hold a movie before returning it using the same predictors that were used in regression (1) 
to predict the should minus want scores survey participants gave to a sample of 500 Quickflix movies.

The regression in Table 4 includes the same control variables, fixed effects, and clustered standard errors that were used in regression (2). The correlation between the coefficients on each of the movie descriptor variables used as predictors in regression (5) and the coefficients on each of these same predictor variables in regression (1) is 0.53 ( $\mathrm{p}$-value $<0.01$; see Figure 3 for illustration). This suggests that our SMW scores capture the essence of those characteristics of a DVD that predict how long a Quickflix customer will postpone watching it.

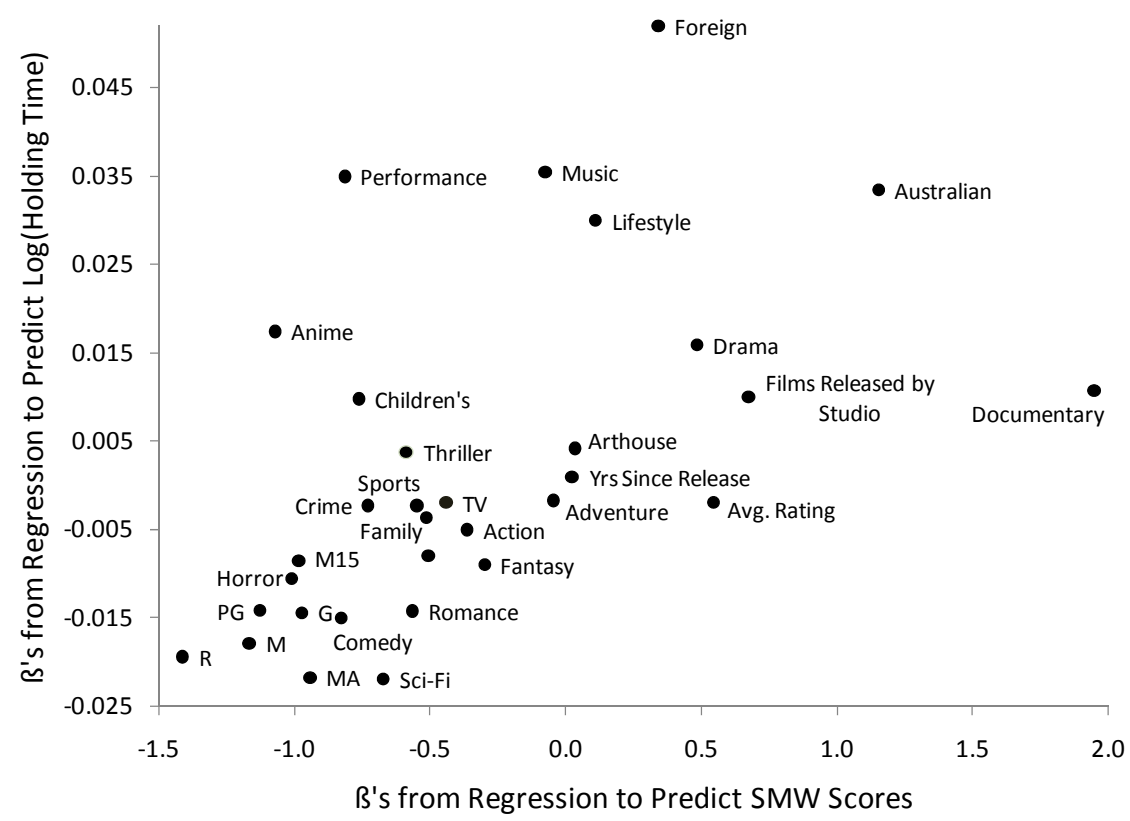

Figure 3: Illustration of the correlations between the $\beta$ coefficient estimates in Regressions (1) and (5). 
Table 4

THE EFFECT OF A MOVIE'S QUANTIFIABLE ATTRIBUTES ON HOLDING TIME

\begin{tabular}{|c|c|}
\hline & $\begin{array}{c}\text { Log(Holding Time) } \\
\text { (5) }\end{array}$ \\
\hline Number of Characters in Film Title $\times 10^{2}$ & -0.0079 \\
\hline Number of Films Released by Same Studio in Quickflix Library $\times 10^{3}$ & 0.0129 \\
\hline Average User Rating of Film $\times 10^{2}$ & -0.0019 \\
\hline Years Since Film's Release in Theaters & $0.0010^{\star \star *}$ \\
\hline Days Since Film's Release on DVD x $10^{4}$ & $0.0787^{\star \star \star}$ \\
\hline Film Rated R & -0.0194 \\
\hline Film Rated PG & -0.0142 \\
\hline Film Rated MA & -0.0217 \\
\hline Film Rated M15 & -0.0086 \\
\hline Film Rated M & -0.0179 \\
\hline Film Rated G & -0.0144 \\
\hline Action Film & -0.0050 \\
\hline Adventure Film & -0.0017 \\
\hline Anime Film & 0.0174 \\
\hline Arthouse Film & 0.0042 \\
\hline Australian Film & $0.0334^{\star \star \star}$ \\
\hline Children's Film & 0.0098 \\
\hline Comedy Film & $-.01496^{\star \star \star}$ \\
\hline Crime Film & -0.0023 \\
\hline Documentary Film & 0.01069 \\
\hline Drama Film & $0.0159^{\star \star \star}$ \\
\hline Family Film & -0.0037 \\
\hline Fantasy Film & -0.0090 \\
\hline Foreign Film & $0.0520^{\star \star \star}$ \\
\hline Horror Film & -0.0105 \\
\hline Lifestyle Film & $0.0299^{*}$ \\
\hline Music Film & $0.0354^{\star \star *}$ \\
\hline Performance Film & $0.0349^{*}$ \\
\hline Romance Film & $-0.0142^{\star \star}$ \\
\hline Science Fiction Film & $-0.0219^{\star \star \star}$ \\
\hline Sports Film & -0.0023 \\
\hline Television Film & -0.0020 \\
\hline Thriller Film & 0.0038 \\
\hline Movie's Rank in Customer's Queue When Shipped & $-0.0003^{\star *}$ \\
\hline Days Movie Spent in Customer's Queue & $0.0001^{\star \star *}$ \\
\hline Customer's DVD Rentals Since January 1, 2006 & $0.0017^{\star \star *}$ \\
\hline Movie's Length (in minutes) & $0.0001^{\star \star *}$ \\
\hline Day of the Week Movie Shipped Fixed Effects & Yes \\
\hline Week of the Year Fixed Effects & Yes \\
\hline Customer Fixed Effects & Yes \\
\hline Observations & 101,545 \\
\hline Customers & 4,474 \\
\hline $\mathbf{R}^{2}$ & 0.5301 \\
\hline
\end{tabular}

\subsection{Customer-Level Analyses}

In addition to examining average levels of myopia across customers by including all individuals in our database in regressions with customer fixed effects and clustered standard errors, we replicate our 
primary analyses at the customer level. This allows us to determine what percentage of customers appear to exhibit myopia as well providing a second measure of the magnitude of the effects of interest.

In our first set of customer-level analyses, for each of the 4,474 customers included in the holding time regressions described in Section 4.1 we run a regression to predict the logarithm of the number of days a customer holds a movie before returning it with a single predictor variable: the movie's SMW score. Of the 3,915 customers who rented enough movies for us to estimate a beta coefficient and associated standard error for the single predictor variable in their OLS regression, the coefficient estimated on the SMW score variable is positive $55 \%$ of the time (binomial test, $\mathrm{N}=3,915, \mathrm{H}_{0}: 55.3 \%=44.7 \%$ can be rejected, $\mathrm{p}<0.001$ ). The weighted average beta estimate on our primary predictor variable (weighted by the inverse of a coefficient estimate's standard error to account for differences in the precision of each beta estimate) is 0.047 . The average number of observations included in these 3,915 regression equations was 25.7 (standard deviation $=20.9)$.

In our next and final set of customer-level analyses, for each of the 3,095 customers included in the regressions examining reversals in preferences described in Section 4.2, we run a regression to predict the probability of a reversal in preferences at the individual level with a single predictor variable: the movie 1 SMW premium. Of the 976 customers who exhibited enough reversals in preferences for us to estimate a beta coefficient and associated standard error for the single predictor variable in their OLS regression, the coefficient estimated on the movie 1 SMW premium is positive $56 \%$ of the time (binomial test, $\mathrm{N}=976, \mathrm{H}_{\mathrm{o}}: 55.5 \%=44.5 \%$ can be rejected, $\mathrm{p}<0.001$ ). The weighted average beta estimate on our primary predictor variable (again, weighted by the inverse of a coefficient estimate's standard error to account for differences in the precision of each beta estimate) is 0.032 . The average number of observations included in these 976 regression equations was 7.5 (standard deviation $=3.7)$.

The results of these analyses are consistent with the findings we presented in sections 4.1 and 4.2 and provide alternative effect size estimates. The effect sizes estimated here are two-and-a-half to three times as large as those estimated in our fixed effects regressions. These analyses also give us a sense of 
the percentage of customers in our data who exhibit myopia, although it is important to note that the customers included in these analyses are on average more frequent renters than those included in our primary analyses, which may bias these numbers.

\subsection{Addressing Alternative Explanations for Our Findings and Seeking Evidence of Learning}

Besides myopia, there are a number of potential alternative explanations for our findings, which we will attempt to rule out in this section. The first is that movies with higher SMW scores are also movies that people like more. As a result of this, people hold onto these types of movies for longer periods of time in order to watch them repeatedly, lend them to friends, or draw out the viewing experience. There are several reasons we believe we can rule out this explanation for our results. First, assuming a movie's popularity (which we quantify as the number of times it was rented in our data set divided by the number of days when it was available for rent) is a reasonable proxy for how well people like a movie, if this alternative explanation were correct, we would expect a movie's SMW score to be positively correlated with its popularity. In fact, we find that this popularity measure is significantly negatively correlated with a movie's SMW score across the 17,258 movies in our dataset $(\rho=-0.11 ; p<0.001)$.

Other ways to examine the plausibility of this alternative hypothesis are to see if our primary results change if we: (a) include popularity as a predictor in our primary regression analyses or (b) restrict our primary regression analyses so they only include observations involving popular movie rentals.

When we add the popularity measure described above to the set of explanatory variables included in regression (2) to predict a movie's holding time, we find that a film's popularity is significantly negatively associated with its holding time, and the addition of this variable does not meaningfully affect the estimated coefficient on a movie's SMW score or its statistical significance. Similarly, when we run regression (2) to predict a movie's holding time and restrict our sample to include rentals of only the 200 most popular Quickflix movies, our main effect remains significant, and our estimate of its effect size increases by over $30 \%$. Turning to our analyses of reversals in preferences, including a variable that quantifies the popularity premium of the first of two sequentially rented movies when we run regression (3) to predict 
the probability of a reversal in preferences also has no meaningful effect on our estimate of the coefficient on our primary predictor variable (the movie 1 SMW premium) or on its statistical significance. In addition, movie 1's popularity premium is negatively related to the probability of a reversal in preferences. Finally, restricting our analysis of reversals in preferences to include only particularly popular film titles again increases the estimated beta on the movie 1 SMW premium, this time by nearly $90 \% .^{5}$ Together, these results suggest that our findings are not driven by people's preference for should movies and resulting tendency to hold onto these types of films for longer.

Another potential alternative explanation for our results is that people rarely find themselves in the mood for a should movie, but when they do, having a should movie on hand is extremely valuable. As a result, people hold should movies longer than want movies, but it is rational for them to do so because of the high "option value" of these films. If this is truly the source of our finding that should films are held longer than want films, and if it is not a rationalization people provide for their myopia, then we would not expect to see the same customer with more experience renting from Quickflix attenuate her tendency to hold should films longer than want films. However, if what we are observing is irrational procrastination, customers with more DVD rental experience ought to learn about their myopia and take steps to curb it. To pit the alternative explanations for our primary findings outlined above against one another, we run a new regression to predict a movie's holding time in which we interact the (standardized) number of DVDs a customer has rented from Quickflix since January 1 ${ }^{\text {st }}, 2006$ (our proxy for "experience" with DVD rentals) with a movie's SMW score (see Table 5, Regression 6). The significant negative coefficient on the interaction term in regression (6) indicates that the more experience a customer has renting DVDs from Quickflix, the less that customer will procrastinate about returning should films. ${ }^{6}$ This result suggests that customers are learning about their myopia and taking steps to curb it as

\footnotetext{
${ }^{5}$ In this case we restrict ourselves to the top 1,000 films because we lose too many observations to estimate withinperson effects with any precision if we restrict to ourselves to observations involving two top 200 films rented sequentially.

${ }^{6}$ Customer-level regressions run on customers who rented more than 20 DVDs during the period examined and which include the predictors SMW score, rentals year-to-date and the interaction between these two terms also yield
} 
they gain experience renting DVDs. ${ }^{7}$ If customers were holding should movies longer than want DVDs for a rational reason (such as the high option value of should movies), we would not expect to see this pattern of "learning." We thus believe we can rule out this alternative "rational" explanation for our results.

Table 5

THE EFFECT OF A CUSTOMER'S EXPERIENCE ON HOW MUCH A MOVIE'S SMW SCORE AFFECTS ITS HOLDING TIME

\begin{tabular}{|c|c|}
\hline & $\begin{array}{c}\text { Log(Holding Time) } \\
(6)\end{array}$ \\
\hline Should Minus Want Score & $\begin{array}{l}0.0208^{\star \star \star} \\
(0.0018)\end{array}$ \\
\hline (SMW Score) x (Z Customer's DVD Rentals Since Jan. 1, 2006) & $\begin{array}{l}-0.0079^{* * \star} \\
(0.0017)\end{array}$ \\
\hline Z Customer's DVD Rentals Since January 1, 2006 & $\begin{array}{l}.02951^{\star \star \star} \\
(0.0042)\end{array}$ \\
\hline Movie's Rank in Customer's Queue When Shipped & $\begin{array}{l}-0.0002 \\
(0.0001)\end{array}$ \\
\hline Days Movie Spent in Customer's Queue & $\begin{array}{l}0.0002^{\star \star \star} \\
(0.0000)\end{array}$ \\
\hline Movie's Length (in minutes) & $\begin{array}{l}0.0001^{\star \star \star} \\
(0.0000)\end{array}$ \\
\hline Day of the Week Movie Shipped Fixed Effects & Yes \\
\hline Week of the Year Fixed Effects & Yes \\
\hline Customer Fixed Effects & Yes \\
\hline Observations & 101,545 \\
\hline Customers & 4,474 \\
\hline $\mathbf{R}^{2}$ & 0.5295 \\
\hline $\begin{array}{l}\text { Column (6) reports OLS coefficients from a regression of the log of } \\
\text { customer held a movie on the movie's should minus want score an } \\
\text { variable with the number of films the customer has rented since Jar } \\
\text { for the other variables listed. Robust standard errors clustered at th } \\
\text { parentheses. }{ }^{\star},{ }^{\star *} \text {, and }{ }^{\star \star \star} \text { denote significance at the } 10 \text { percent, } 5 \\
\text { levels, respectively. }\end{array}$ & $\begin{array}{l}\text { number of days a } \\
\text { e interaction of this } \\
\text { y } 1,2006, \text { controlling } \\
\text { ustomer-level are in } \\
\text { cent, and } 1 \text { percent }\end{array}$ \\
\hline
\end{tabular}

To further assess the plausibility of the alternative explanations discussed above, we also conducted a survey in which we asked people with experience renting DVDs what they think has caused them in the past to exhibit the type of behavior we detected in our primary analyses. One hundred and twenty-one subjects who signed up to participate in online paid polls conducted by the market research firm Zoomerang gave a response other than "not applicable" to a question asking why, if they had ever

a negative interaction coefficient significantly more often than not (binomial test, $\mathrm{N}=1,900, \mathrm{H}_{0}: 51.4 \%=48.6 \%$ can be rejected, $\mathrm{p}<0.05$ ).

${ }^{7}$ Running the same type of analysis with our preference reversal regression specification yields a coefficient on the interaction between the number of rentals year-to-date when movie 1 is rented and the movie 1 SMW premium that is directionally consistent with this story (more rentals attenuate the impact of the movie 1 SMW premium on the probability of a preference reversal), but this effect is not statistically significant. However, these regressions have con- 
rented a should movie before a want movie but returned the movies out of order, they thought they did so. Of the three possible explanations subjects could select, just $4.1 \%$ of respondents believed they had exhibited this behavior because they "liked the should DVD so much more than the want DVD that they held onto it longer." On the other hand, $64.5 \%$ of respondents claimed they "watched the want DVD first because when the moment to choose a DVD to watch arose, the want DVD was just more appealing than the should DVD” - an explanation suggesting that myopia drives the time-inconsistent preferences we observe in our data set. The remaining $31.4 \%$ of respondents believed they "watched the want DVD first because [they were] holding the should DVD on hand so that [they] would have it available for when [they were] in the mood to watch it," an explanation consistent with a rational "option value" story or with the possibility that myopic renters are poor forecasters of their future moods but naïve about this weakness. These survey results provide additional evidence that the time-inconsistent preferences we observe in our Quickflix data set result primarily from myopia. When asked to explain our findings, the vast majority of subjects with online DVD rental experience point to the explanation we classify as "procrastination" (binomial test, $\mathrm{N}=121, \mathrm{H}_{\mathrm{o}}: 64.5 \%=35.5 \%$ can be rejected, $\mathrm{p}<0.001$ ).

One could construct other explanations for our results besides those addressed above and besides our explanation that renters are myopic. However, in light of the considerable body of research suggesting that people are myopic, including Read et al.’s (1999) laboratory study of myopia and movie choice, and in light of the analyses presented above to rule out alternative explanations, we believe that myopia is the most compelling explanation for our findings.

\section{Discussion}

The results presented above demonstrate that, consistent with the combined predictions of models of myopia and our definition of relative should and want goods, the more should characteristics and the fewer want characteristics a DVD has, the longer a Quickflix customer will postpone watching that DVD. Also consistent with models of individuals as myopic and our definitions of relative want and should 
goods, the probability that a customer will exhibit a reversal in preferences increases when two films are rented sequentially the relatively more should and fewer want characteristics the first film rented has than the second.

Our analyses offer the first field demonstration that combining a model of consumers as myopic with a model of goods as ranging from extreme wants to extreme shoulds correctly predicts the way people's rankings of a series of goods will change when they choose for the present versus the future. Our findings are consistent with past work on time-inconsistent preferences, but also extend previous field studies of myopia and choice, which have only examined whether people are less likely to engage in a should option when choosing for now versus later. Our evidence suggests that the effects of myopia on which alternative people will select given an array of choices can be quite meaningful in the field. We believe this discovery should increase the importance researchers assign to the results of previous laboratory studies about the effects of myopia on decision making.

In addition, our analyses provide early evidence that experience may attenuate people's myopic behavior. One implication of this finding is that parties with more experience making decisions in a certain domain may better recognize people's tendency to act myopically when making choices in that domain and may take advantage of this "weakness" in their-less experienced counterparts. For example, baseball team managers with extensive experience negotiating players' contracts may realize that players are myopic and value up-front pay (i.e., signing bonuses) more than their yearly salary, an observation that could allow those managers to structure deals that are psychologically more attractive to players, yet less beneficial to them from a normative perspective and more attractive to the sophisticated managers. Policymakers might want to prevent experienced participants in markets who are sophisticated about myopia from taking advantage of less-experienced, myopic individuals.

Our findings also have implications for companies that loan items to consumers. Such companies should be able to forecast how long customers will hold different items they have borrowed based on the

size. 
extent to which those items are should versus want goods. Specifically, we believe rental companies would be wise to expect customers to return want goods faster than should goods. Our results have similar implications for online and catalogue retailers that offer different shipment options to customers. Our findings suggest that want goods will be in higher demand for immediate delivery than for delayed delivery, while should goods will exhibit the opposite demand pattern. Finally, our study has implications for consumers, many of whom may be doing an ineffective job of maximizing their utility over time due to their impulsivity. Such consumers would presumably benefit from becoming aware of their myopia, as this would allow them to take steps to curb harmful impulsive behaviors.

\section{Acknowledgments}

We gratefully acknowledge helpful and insightful input from two anonymous referees, J. Beshears, G. Loewenstein, D. Laibson, S. Mullainathan, N. Ashraf, D. Parkes, K. McGinn, S. Woolverton, W. Simpson, S. Hanson, A. Sunderam, D. Moore, D. Chugh, members of Max's Non-Lab, and participants in the Harvard Economics and Psychology Seminar. In addition, we are thankful to Z. Sharek who helped us design and implement our survey to measure a film's should minus want score, to M. Norton and L. Anik who helped us run our survey to ask people why they hold should films longer than want films, and to M. McCoy, J. Packi, E. Siegle, E. Weinstein and K. Chance who helped us by giving films want and should ratings. We also appreciate the cooperation of our contacts at Quickflix and the help of A. Elberse in facilitating our relationship with Quickflix.

\section{References}

Ainslie, G. (1992). Piconomics. Cambridge University Press, Cambridge, UK.

Angeletos, G., Laibson, D., Repetto, A., Tobacman, J., \& Weinberg, S. (2001). The hyperbolic consumption model: Calibration, simulation, and empirical evaluation. Journal of Economic Perspectives 15(3) $47-68$.

Ariely, D. \& Wertenbroch, K. (2002). Procrastination, deadlines, and performance: Self-control by precommitment. Psychological Science $13219-224$. 
Ashraf, N., Karlan, D. \& Yin, W. (2006). Tying Odysseus to the mast: Evidence from a commitment savings product in the Philippines. Quarterly Journal of Economics 121(2) $635-672$.

Bazerman, M.H., Tenbrunsel, A.E., \& Wade-Benzoni, K.A. (1998). Negotiating with yourself and losing: making decisions with competing internal preferences. Academy of Management Review 23225 241.

Erev, I. \& Roth, A. (1998). Predicting how people play games: Reinforcement learning in experimental games with unique, mixed strategy equilibria. American Economic Review 88 848-881.

Fudenberg, D. \& Levine, D. (2006). A dual self model of impulse control. American Economic Review 96 1449-1476

Frederick, S., Loewenstein, G. \& O’Donoghue, T. (2002). Time discounting and time preference: A critical review. Journal of Economic Literature 40(2) 351 - 401.

Goldstein, D. G. \& Goldstein, D. C. (2006). Profiting from the long tail. Harvard Business Review 84(6) 24-28.

Khan, U., Dhar, R. \& Wertenbroch, K. (2005). A behavioral decision theory perspective on hedonic and utilitarian choice. In S. Ratneshwar and D.G. Mick (Eds.), Inside Consumption: Frontiers of Research on Consumer Motives, Goals, and Desires, (pp. 144 - 165). Routledge, London.

Khan, U. (2007). Where there is a way, is there a will? The effect of future choices on current preferences. Journal of Experimental Psychology - General 136(2) 277-288.

Kirby, K. N. (1997). Bidding on the future: Evidence against normative discounting of delayed rewards. Journal of Experimental Psychology $12654-70$.

Kirby, K.N. \& Herrnstein, R.J. (1995). Preference reversals due to myopic discounting of delayed rewards. Psychological Science 6(2) $83-89$.

Kirby, K.N. \& Marakovic, N.N. (1996). Delayed-discounting probabilistic rewards rates decrease as amounts increase. Psychonomic Bulletin and Review 3(1) 100 - 104. 
Laibson, D. (1996). Hyperbolic discount functions, undersaving and savings policy. NBER working paper w5635.

Lichtenstein, S., \& Fischhoff, B. (1980). Training for calibration. Organizational Behavior and Human Decision Processes 26(2) 149-171.

Loewenstein, G. (1996). Out of control: Visceral influences on behavior. Organizational Behavior and Human Decision Processes 65(3) 272 - 292.

Loewenstein, G. \& Prelec, D. (1992). Anomalies in intertemporal choice: Evidence and an interpretation. Quarterly Journal of Economics 107 573-597.

Loewenstein, G. \& Thaler, R. (1989). Anomalies: Intertemporal choice. The Journal of Economic Perspectives 3(4) $181-193$.

Malmendier, U. \& Della Vigna, S. (2006). Paying not to go to the gym. American Economic Review 96(3) 694-719.

McClure, S.M., Laibson, D., Loewenstein, G., \& Cohen, J.D. (2004). Separate neural systems value immediate and delayed monetary rewards. Science 306, $503-507$.

Milkman, K.M., Rogers, T., \& Bazerman, M.H. (2008). Harnessing our inner angels and demons: What we have learned about want/should conflicts and how that knowledge can help us reduce shortsighted decision making. Perspectives on Psychological Science 3(4) 324 - 338.

Milkman, K.L, Rogers, T. \& Bazerman, M.H. (2007). I'll have the ice cream soon and the vegetables later: Decreasing impatience over time in online grocery orders. HBS Working Paper \#07-078.

Navarick, D.J. (1982). Negative reinforcement and choice in humans. Learning and Motivation 13361 377.

O’Donoghue, T. \& Rabin, M. (1999). Doing it now or later. The American Economic Review 89(1) 103 124.

Oster, S. \& Scott Morton, F.M. (2005). Behavioral biases meet the market: the case of magazine subscription prices. Berkeley Electronic Journals Economic Analysis and Policy - Advances 5(1). 
Phelps, E.S. \& Pollack, R. (1968). On second-best national saving and game-equilibrium growth. Review of Economic Studies 35185 - 199.

Phillips, Matt (2006). For some Netflix users, red envelopes gather dust, Wall Street Journal Online, July $8,2006$.

Read, D., Loewenstein, G., \& Kalyanaraman, S. (1999). Mixing virtue and vice: combining the immediacy effect and the diversification heuristic. Journal of Behavioral Decision Making 12257 - 273.

Read, D. and van Leeuwen, B. (1998). Predicting hunger: The effects of appetite and delay on choice. Organizational Behavior and Human Decision Processes 76(2) 189 - 205.

Read, D. (2001). Intrapersonal dilemmas. Human Relations 54(8), 1093 - 1117.

Rogers, T \& Bazerman, M.H. (2008). Future lock-in: Future implementation increases selection of ‘should’ choices. Organizational Behavior and Human Decision Processes 106(1), 1 - 20.

Shrout, P.E. \& Fleiss, J.L. (1979). Intraclass correlations: Uses in assessing rater reliability. Psychological Bulletin 86(2) 420 - 428.

Solnick, J., Kannenberg, C., Eckerman, D., \& Waller, W. (1980). An experimental analysis of impulsivity and impulse control in humans. Learning and Motivation 11(1) 61 - 77.

Strotz, R. (1956). Myopia and inconsistency in dynamic utility maximization. Review of Economic Studies $23165-180$.

Thaler, R.H. (1981). Some empirical evidence on dynamic inconsistency. Economic Letters 8201 - 207.

Thaler, R. H., \& Shefrin, H. (1981). An economic theory of self control. Journal of Political Economy 89 $392-406$.

Trope, Y. \& Fishbach, A. (2000). Counteractive self-control in overcoming temptation. Journal of Personality and Social Psychology 79(4) 493 - 506.

Tugend, Alina (2006). Getting movies from a store or a mailbox (or just a box). New York Times, August 5, 2006. 
Wertenbroch, K. (1998). Consumption self-control by rationing purchase quantities of virtue and vice. Marketing Science 17(4) 317 - 337. 
This page is intentionally blank. Proper e-companion title page, with INFORMS branding and exact metadata of the main paper, will be produced by the INFORMS office when the issue is being assembled. 


\title{
Appendix. Should/Want DVD Survey
}

\author{
Research Participation Consent Form \\ DVD Categorization: An Investigation of Different Types of Films and Television Programs
}

The purpose of this study is to obtain ratings of a sample of DVDs along two different dimensions. In the study, you will be provided with short descriptions of a sample of 60 DVDs and asked to rate each DVD's conformity to categories we will describe. Your participation in this study will take about 45 minutes. If you have any questions about the study, please e-mail us, and we will respond promptly.

For your participation in the study, you will receive a minimum of $\$ 15.00$.

You will be rating DVDs along category scales that range from 1 to 7 . You will be given an "accuracy" score based on your DVD ratings. For each DVD you classify within one point of the average rating across survey participants who also rated that DVD, your accuracy score will be increased by one. The $20 \%$ of participants who receive the highest accuracy scores will be paid a bonus of $\$ 10.00$.

Your participation in this study is purely voluntary, and you may withdraw your participation or your data at any time without any penalty to you. Your participation in this study will remain confidential, and your identity will not be stored with your response data.

If you have read the description of this study, your questions have been answered, and you give your consent to participate, please click on the link below and you will be redirected to the online study.

\section{Study Link: DVD Survey}

Harvard University has a Standing Committee on the Use of Human Subjects in Research (CUHS) to which complaints or problems concerning any research project may, and should, be reported if they arise. If you have concerns about this project, please contact Toni Wegner at twegner@hbs.edu or telephone: 617-496-9952.

\section{[NEXT PAGE]}

\section{DVD Survey}

Unless you are instructed to do so, please do not use the back or refresh buttons on your browser during this survey.

Dear Survey Participant,

Thank you in advance for taking the time to participate in this research project. Before beginning the survey, you will be introduced to two concepts. You will then be briefly quizzed on these concepts (to insure that you understand them) before you are asked to complete the survey.

\section{Concept Introduction}

"Want" DVDs: As part of this survey, you will be asked to score a number of films and tv shows on a scale from 1 (not a "want" DVD) to 7 (a strong "want" DVD). A "want" DVD is one that someone would choose to see for the pure enjoyment of it. There may be additional reasons for seeing the DVD - it may be intellectually stimulating or recommended by people the viewer would like to impress, but these reasons are not to be taken into account when determining the "want" score of the DVD. The "want" score is intended to reflect the extent to which someone's decision to watch this DVD would be indulgent and pleasure-based. Example of a strong "want" DVD: A summer blockbuster, featuring attractive movie stars, with an appealing advertising campaign.

"Should" DVDs: You will also be asked to rate a number of DVDs on a scale from 1 (not a "should" DVD) to 7 (a strong "should" DVD). A "should" DVD is one that someone would feel compelled to watch. This might be because the DVD is expected to improve the viewer in some way - intellectually, socially (because of recommendations from people the viewer would like to impress), or otherwise. The "should" score ought to reflect the extent to which someone's choice to watch the DVD would be made for virtuous, self-improving reasons, regardless of other poten- 
tial factors. Example of a strong "should" DVD: A DVD that audiences feel compelled to watch for their betterment as human beings - in other words, for reasons besides sheer pleasure.

IMPORTANT: When rating the DVDs in this survey, you should imagine that someone is standing in a video rental store and has just chosen to rent the DVD in question. Give the DVD "should," and "want" scores based on the feelings you imagine the renter has toward the DVD that he or she is renting. You should not give the DVDs in this survey "should" and "want" scores based on how much you personally want to see them or feel that you should see them.

Please note that "want" and "should" DVDs are not mutually exclusive - a DVD may receive both a high "want" score and a high "should" score.

\section{Comprehension Check}

1. A "want" DVD:

a. is a DVD that someone would only watch because of its outstanding reviews from critics:

C True False

b. is a DVD that someone would choose to watch for the frivolous pleasure of doing so:

$C_{\text {True }}$ False

2. A "should" DVD:

a. cannot also receive a high "want" score: $\mathbf{C}$ True $\mathbf{C a l s e}$

b. is a DVD that someone would feel compelled to watch in order to improve him or herself:

C True False

3. When answering the questions in this survey you should:

a. imagine that someone has elected to see the DVD in question, and give it a "should" score and a

"want" score based on the motivations you imagine that person must have for choosing to watch

the DVD: $\mathbb{C}$ True ${ }^{2}$ False

b. simply call upon your own feelings about how much you "want" to see a DVD or think you

"should" see a DVD: True False

Submit Comprehension Check

[NEXT PAGE]

\section{Below are the correct answers to the comprehension check.}

Questions you answered correctly are marked with a ***, and questions you answered incorrectly are marked with an $\mathbf{X}$. If you would like to review our concept definitions in another browser window, please click here. When you have finished reviewing the answers to the comprehension check, please click on the button labeled "Proceed."

\section{Comprehension Check}

1. A "want" DVD:

a. is a DVD that someone would only watch because of its outstanding reviews from critics: (Correct Answer -- False) ***

b. is a DVD that someone would choose to watch for the frivolous pleasure of doing so: (Correct Answer -- True) $* * *$

2. A "should" DVD:

a. cannot also receive a high "want" score: (Correct Answer -- False) ***

b. is a DVD that someone would feel compelled to watch in order to improve him or herself: (Correct Answer -- True) ***

3. When answering the questions in this survey you should:

a. imagine that someone has elected to see the DVD in question, and give it a "should" score and a "want" score based on the motivations you imagine that person must have for choosing to watch the DVD: (Correct Answer -- True) *** 
b. simply call upon your own feelings about how much you "want" to see a DVD or think you "should" see a DVD: (Correct Answer -- False) ***

Proceed

[NEXT PAGE]

\title{
Thank you for completing our "comprehension check."
}

If you would like to gather more information than what is provided in this survey about any of the DVDs in question, please feel free to do so by browsing the internet.

-- Page 1 of 6 --

\section{Please Answer the Following Questions}

Have you ever watched:

(1) The Motorcycle Diaries? $\boldsymbol{C}_{\text {Yes }}$

Submit Survey Responses

[NEXT PAGE]

-- Page 2 of 6 --

For a review of concept definitions, click here at any time.

Please Give the Following DVDs "Want" Scores -- these are all DVDs you have seen

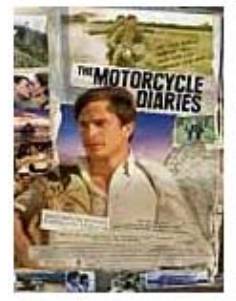

\author{
The Motorcycle Diaries (2004) \\ Diarios de motocicleta
}
This film tells the incredible true story of a 23-year-old medical student from Argentina, Che Guevara yes, that Che, played here by Gael
Garcia Bernal), who motorcycled across South America with his friend Alberto Granado (Rodrigo de la Serna) in 1951-52. The trek became a personal odyssey that ultimately crystallized the young man's budding revolutionary beliefs. Based on Che's own diaries of the trip.
Starring: Gael Garcia Bernal, Rodrigo de la Serna, More Director: walter Salles
R For language

Genre: Foreign Format: Widescreen, More Language: Spanish, More

Subtitles: English, More

Awards: Academy Award

Winner, More

More Movie Details

(61) Please give the DVD The Motorcycle Diaries a "want" score.

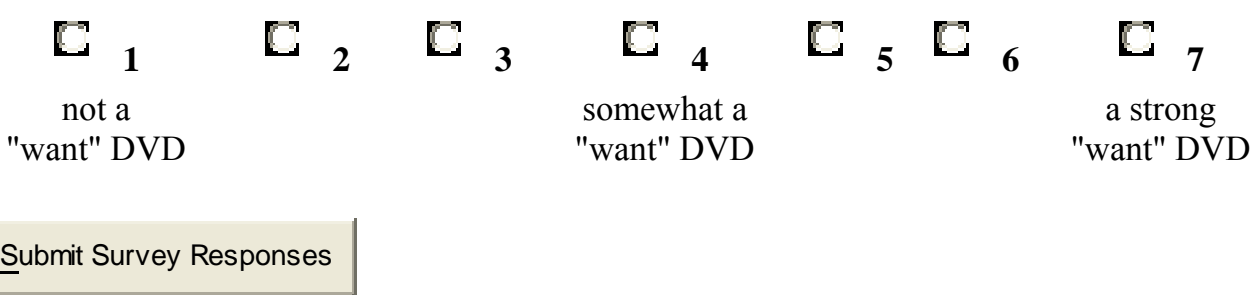

\section{[NEXT PAGE]}

Subsequent portions of this survey use the same display as above but ask participants to rate films along different continuous Likert scales. The other Likert scale in this survey is anchored by: "not a should film" - "somewhat a should film" - "a strong should film". Subjects are asked separately about films they have seen and films they have not seen. 